\section{Military Technical College Kobry El-Kobbah, Cairo, Egypt}

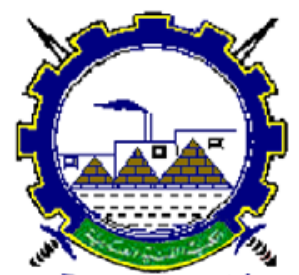

I.C.E.E.2014 $7^{\text {th }}$ International Conference

on

Chemical \& Environmental

Engineering

27 - 29 May, 2014.

(CEED-3)

\title{
Sustainable development: Potential of Reusing Water Treatment Plant Sludge In Brick Manufacturing
}

\author{
Maha A. Tony ${ }^{1},{ }^{2}$, , E. Ashour ${ }^{3}$
}

\begin{abstract}
Alum sludge produced in large amounts from the drinking water treatment plants (WTP) as a result of using aluminium sulphate as a primary coagulant. The sludge disposed during the various water treatment processes can be a major concern for (WTP). A large quantity of sludge is generated each year from those water treatment plants in Egypt. Disposing the sludge to the nearest watercourse is the common practice in Egypt, which accumulatively rise the aluminum concentrations in water and consequently in human bodies. Disposal of sludge in a way that is economically and environmentally sustainable is a major challenge faced by WTPs around the globe. In this study, the alum sludge generated during water treatment was used as a partial substitute for brick manufacturing process. In this study, different series of sludge and cement proportioning ratios were studied, which exclusively involved the addition of sludge with ratios of 5 to $30 \%$ of the total weight of brick mixture. In this paper, the physical and mechanical properties of sludge-cement bricks, such as loss on ignition (LOI), water absorption, and compressive strength, are investigated. The results from this study indicate that alum sludge could be used as a partial substitute in commercial cement bricks to a maximum of $30 \%$ without compromising the strength of the bricks.
\end{abstract}

\section{Key words:}

water works plants, Alum sludge, Sludge disposal, Brick manufacturing

1 Green Chemistry Centre of Excellence, Department of Chemistry, University of York, York, UK, YO10 5DD

2 Basic Engineering Science Department, Faculty of Engineering, Minoufiya University, Minoufiya, Shebin Elkoum, 32511, Egypt

* Corresponding author: Maha Tony, Phone: +2 048 2221549; Fax: +2 048 2235695; Email:maha tony1@yahoo.com

3 Chemical Engineering Department, Faculty of Engineering, Minia University, Minia,61111, Egypt 


\section{Introduction}

Brick is one of the most important construction elements. The history of brick manufacturing goes back 8000 years when the fabrication of the earliest sun dried clay bricks was discovered. Sludge generated at water treatment plants should be treated and handled in an environmentally sound manner [1].

Alum salt is generally used to promote coagulation in the production of clean drinking water which results in the generation of significant quantities of drinking water sludge. Such sludge is characterized by high water content (low solid concentration), high resistance to mechanical dewatering and is difficult to dispose of or handle [2]. A large quantity of sludge is generated each year from those water treatment plants in Egypt. Most of the focus has been on awareness building and the development of water treatment system for purification of drinking water. However, the disposal of aluminium rich sludge generated from the treatment processes is one of the issues that have received little attention from the sponsors of the technologies and the users [3].

Traditionally, Disposing the sludge to the nearest watercourse which is the general practice in Egypt, thus, accumulatively rise the aluminium concentrations in water and consequently in human bodies. Disposal of sludge in a way that is economically and environmentally sustainable is a major challenge faced by WTPs around the globe. There is a strong demand for environmentally safe reuse of and effective disposal methods for alumnium contaminated sludge out of water treatment plant due to the increasing amount of sludge generated by the water treatment plants in Egypt. Legislative pressure appears likely to curtail this mode of disposal, with the result that considerable effort is being expended in the examination of alternate means of sludge disposal. For instance, incineration is costly and contributes to air pollution and landfill space is becoming scare. A possible long-term solution appears to be recycling of the sludge and using it for beneficial purposes. One technique that is available to treat hazardous waste is solidification that stabilizes and solidifies components of waste. The solidified product is disposed off to a secure landfill site or it can be recycled as construction material like bricks if it meets the specific strength requirement and can be shown to leach toxic pollutants within acceptable limits $[4,5]$.

For this and other reasons, numerous attempts have been made to re-use of such sludge [6]. In instances, conjunctive evidences from literature have shown that alum sludge can be applied for different uses. For instance, Feenstra et al., [4] Elangovan and Subramanian [7] used water treatment sludge in brick manufacturing. Moreover, Yang et al., [8] applied the dewatered alum sludge for phosphorous removal.

For the above drawbacks and reasons, the re-using of alum sludge from water works plants is used to produce brick units. The brick made of mixtures of cement and water treatment plant sludge with various ratios that meet the obligatory values of compressive strength and water absorption assigned by the Egyptian Standard Specifications for load bearing bricks. Also it was objected in this research to produce bricks that can compete with most of the commercial brick types available in the Egyptian market.

\section{Objective of the research}

Keeping the above factors in mind, the research work was carried to use this contaminated sludge in making a product, which has some economic values. Therefore, it will definitely reduce the pollution of surface water, ground water and the environment from uncontrolled disposal of aluminium-based contaminated sludge. 
Not only facing the sludge environmental pollution, but also the re-use of that sludge in brick manufacturing. For instance, ornamental bricks are special types of bricks. These are used for decorative work. Real companies use ornamental bricks according to the requirements of customer.

\section{Materials and Methods}

\subsection{Experimental Materials}

Alum sludge samples used during this study were taken from a water treatment plant in Kedwan Station in Minia city, south of Egypt. In this station the treatment process uses aluminium sulfate to treat water taken from The River Nile. Principle properties of this alum sludge are Specific Resistance for Filtration (SRF) of $2.24 \times 10^{13} \mathrm{~m} / \mathrm{kg}$; Suspend Solid (SS) 2,364 mg/l and Moisture Content reached to 97\%. The sludge samples were first left for direct sun drying to be dewatered. Thereafter, the samples collected and washed, then left for overnight drying before subjected to a $110^{\circ} \mathrm{C}$ for have an hour in the oven. The complete chemical composition of (WDAS) sludge is summarized in Table 1. It is clear that there are two major crystalline phases, namly, silica $\left(\mathrm{SiO}_{2}\right)$ and alumina $\left(\mathrm{Al}_{2} \mathrm{O}_{3}\right)$. These results indicate that water treatment plant sludge presents, in its composition, minerals are similar to those commonly occurring in brick manufacturing specially clay brick.

Portland cement used is from a local factory produced according to the Egyptian specifications of 1/6574 (2009) and the European specifications EN 1/197 (2011). Moreover, local stone (Calcite-Dolomite) used in this study was obtained from local brick factory. The

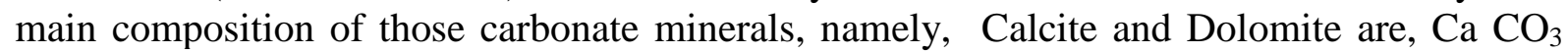
and $\mathrm{CaMg}\left(\mathrm{CO}_{3}\right)_{2}$, respectively.

\subsection{Sample Preparation}

Alum sludge and commercial Portland cement were blended in various proportions and dried at different temperatures to produce cement-sludge bricks. The batching proportions of raw materials required to produce lab-scale brick with nominal dimensions of $(7 \times 7 \times 7)$ centimetres.

The study involved several mixing and preparation techniques. The best sample preparation technique was adopted.

The dried sludge was pulverized using a pestle and mortar. The powder was then sieved through a series of sieves. The sieving process was carried to separate impurities and large particles $(>0.075 \mathrm{~mm})$. The last stage in the preparation step was mixing the raw materials at different ratios of the raw materials. Two different types of brick cubes were prepared LCSBrick (Limestone, Cement and Sludge bricks) and CS-Brick (Cement Sludge bricks). Thereafter, water was added in the range of $75 \%$ to $100 \%$. The samples were poured into the moulds and pressed it t o prevent holes in the brick cubes.

\subsection{Analytical Methods}

The physical and mechanical properties of cement-sludge bricks, such as water absorption L.O.I. (Loss of Ignition), and compressive strength, were investigated.

The absorption test was done according to the standard test in which the brick samples were first dried in the oven at a temperature of $110-115^{\circ} \mathrm{C}$ for a least 48 hours. These were then allowed to cool in the oven with the oven switched off until they reach ambient room temperature and then each weighed on the electronic balance of accuracy of $0.1 \%$. Subsequently, the bricks removed from the bath, dried to surface dry condition, and weighed on the balance again. The water absorption was calculated using the following formula: 


$$
\% \mathrm{~W}=\frac{\mathrm{M}_{2}-\mathrm{M}_{1}}{\mathrm{M}_{2}} \times 100
$$

where:

W, \%: water absorption, \%

$\mathrm{M}_{2}$ : weight of wet mass

$\mathrm{M}_{1}$ : weight of dry mass

Moreover, after the absorption test the change in dimensions was measured for swelling test.

The bricks were then fired at a firing temperature $850{ }^{\circ} \mathrm{C}$ for 3 hours to determine the sample resistance to fire and the L.O.I. is determined.

A universal type compressive strength testing machine (UH-300kNA, Shimadzu type) with a capacity of 30 tons was used for measuring the strength of the brick cubes.

\section{Results and discussion}

\subsection{Effect of sludge amount on the composition of the LCS-bricks}

The result of each test was the average of three bricks, for better reliability of the results. All tests were performed on $(7 \times 7 \times 7)$ centimetres prisms. The test results of the 8 different types of bricks, which include the control brick, were listed below (Table 2). To illustrate, that control brick simulates the commercial cement brick in the Egyptian market. Furthermore, the results were also compared to one of the commercial sand-brick type available in the Egyptian market.

Compressive strength measures the potential for application of the bricks. Compressive strength is affected by the porosity, pore size, and type of crystallization. It is usually defined as the failure stress measured normal to the bed face of the brick. The compressive strength test results are shown in Fig. (1). The compressive strength measured ranged between 5 and $36 \mathrm{~kg} / \mathrm{cm}^{2}$. These values indicates that all of the research brick types could be used in the load except the two brick types that contain more than 15 percent sludge ratio which could be used only in the none load bearing walls. Furthermore, the control brick sample is simulating the common brick in the market with a compressive strength, $40-36 \mathrm{~kg} / \mathrm{cm}^{2}$.

The effect of firing temperature on compressive strength was investigated to determine the bricks durability after firing. An $850{ }^{\circ} \mathrm{C}$ was applied to the prisms, thereafter, the compressive strength and the absorption of water was terminated to monitor the swelling, weight loss and shrinkage after firing.

It is clear from Fig. 2 that completion of the crystallization process and effective sintering was complete at high temperatures. On the contrary, the effect of the sludge ratio attributed to the low silica content in sludge and consequently the decrease in the compressive strength by increasing sludge ratio, which could be attributed to the low silica content of the sludge.

Another ordinary compressive strength using the compressive strength machine test was carried out, but the only difference is that this test was performed to determine the reduction in compressive strength after submergence of brick in water for 24 hours. The results of this test may be considered as an indication for softening under such severe exposure conditions. A considerable reduction in the strength of the brick is anticipated, since the submergence of brick in water for 2 days may cause deterioration and scaling to the brick. The results of this test may predict the behaviour of the brick on the long term. The results of the reduction in compressive strength after 2 days submergence in water are ranged from 8 to 14\% according to the sludge percent ranged from 5 to $10 \%$. Thus, the water absorption increased with increasing the sludge percentage. Similarity, the loss of ignition (L.O.I.) of sludge increased 
from 5 to $10 \%$ is increased from 4 to 6 as the amount organics and oxides in the raw materials in the sludge are increased, which is decreased by the firing. Moreover, the shrinkage due to firing is increased from $2.7 \%$ to $4.2 \%$ by increasing the sludge samples from 5 to $10 \%$. Moreover, the swelling test is carried out to the Series-A, B and C which is increased from 2 to $4 \%$.

This phenomenon could be illustrated by of the sludge the compressive strength decrease could be illustrated by the ratio of silica decrease in mixture and porosity increase. When we increase amount of sludge the water absorption increase as sludge has high porosity. Those results are in accordance with Tay and Show, [9] and Leist et al., [10].

\subsection{Effect of sludge amount on the composition of the CS-bricks}

Cement and sludge brick cubes were moulded in different proportions according to Table 3. As shown in Fig. 3 all of the sludge-CS brick types showed lower apparent compressive strength than SCS-brick.

Water absorption ranged from 8.7 to 13.6 for the CS-bricks that include 20 to $30 \%$ of sludge, respectively. Furthermore, the L.O.I. for the CS bricks recorded a 12.4 to 19.4 for the same percentage of sludge 20 to $30 \%$, respectively. It should be estimated from those results this L.O.I. and water absorption for this type of brick is more than those values recorded for SCS-brick. It could be illustrated by the increase in the amount of sludge which leads to the increasing of water absorption capacity and L.O.I. [11].

Furthermore, the effect of the compressive strength on the sludge percentage is shown in Fig. 3. It is clear from the Fig that increasing the sludge amount in the moulded brick resulted in the decrease in the compressive strength. This phenomenon may be attributed to the amount of silica in the sludge which is increased by increasing the sludge ratio [11]

\subsection{Plant layout of reusing sludge in SCS-Brick manufacturing}

The concept of compressive strength has, as noted above, big implications on engineerings in both their design and material choices. But it has even greater implications on building system, component and product design-which can make the job of the green architect, builder or recycler much easier. Furthermore, the concept in this research also has implication for demolition and recycling of the used bricks at the end of the building service life. Fig, 4 shows a schematic plant diagram that can be used for the brick manufacturing.

Brick can be successfully produced from water treatment plant sludge incorporated with other raw materials; which contain high silica content; under the conditions, mixing proportions, drying temperatures, and manufacturing methods used in this study. More research work need to be conducted to make hollow bricks or blocks using the aluminium based contaminated sludge.

\section{Conclusions}

Results of tests indicated that the sludge proportion and drying were the two key factors determining the quality of brick. The results from this study indicated that alum sludge could be used as a partial substitute in commercial bricks to a maximum of $20 \%$ without compromising the strength of the bricks. Totally, the recommended proportion of sludge in brick making is $5 \%$ by weight to produce a good quality brick using alum contaminated sludge. 
This research work was limited to verify the compressive strength and firing shrinkage of bricks and water absorption. Further study is required for understanding the effect on water. Further study and determined the strength of ornamental bricks at different firing temperature.

\section{Acknowledgements}

The authors wish to appreciate the Water Treatment plant in Kedwan, Elminia, south of Egypt, for providing the sludge samples.

\section{References}

[1] B. Hegazy, Hanan A. Fouad and Ahmed M. Hassanain, Brick Manufacturing From Water Treatment Sludge And Rice Husk Ash, Australian J. Basic Applied Sci. 6(3) (2012) 453-461.

[2] W. R. Knocke and Walkeland D. L. Fundamental characteristics of water treatment plant sludges. Foundation and the American Waterworks Association. J. AWWA 75(10) (1983) 516-523.

[3] Tony Maha A.; Zhao Y.Q.; Fu J.F.; Tayeb A.M., Conditioning of aluminium-based water treatment sludge with Fenton's reagent: Effectiveness and optimising study to improve dewaterability, Chemosphere, 72 (2008) 673-677.

[4] L. Feenstra, J.G.T. Wolde and C.M. Eenstroom, 1997. Reusing Water Treatment Plant Sludge as Secondary Raw Material in Brick Manufacturing, Studies in Environmental Science, 71: 641-645.

[5] Tony, Maha A.; Zhao, Y.Q.; Tayeb, A.M., Exploitation of Fenton and Fenton-like reagents as alternative conditioners for alum sludge conditioning, Journal of Environmental Sciences, Vol. 20, No. 1, 101-105, April, 2009.

[6] D. George B., Beck S. G., Adams V. D., Morgan E. L., Roberts R. O., Holloway C., Lott R. C. and Holt L. K. (1991) Alum sludge in the Aquatic Environment. AWWA Research

[7] Elangovan, C., and Subramanian, K., Reuse of alum sludge in clay brick manufacturing, Water Sci. Technol., 11 (2011) 333-341.

[8] Y. Yang, Y. Q. Zhao, A. Babatunde, O., L. Wang, Y. X., Ren, Y., Han, Characteristics and mechanisms of phosphate adsorption on dewatered alum sludge, Separation and Purification Technology, 51 (2) (2006) 193-200.

[9] Tay, J.-H., Show, K.-Y., Constructive sludge disposal option converting sludge into innovative civil engineering materials. Proceedings of the 7th IAWQ Asia-Pacific Regional Conference, Taipei, Taiwan. (1999) 1023-1028.

[10] M. Leist, Casey, R. J. Caridi, D., The management of arsenic wastes: Problems and prospects. J. Hazard. Mater., 76 (1) (2000) 125-138.

[11] M.O. Ramadan, H.A. Fouad and Ahmed M. Hassanain, Reuse of Water Treatment Plant Sludge in Brick Manufacturing, J. Applied Sci. Res., 4 (2008) 1223-1229. 
Tables

Table 1 Chemical Composition of (WDAS) Sludge

\begin{tabular}{ll}
\hline Ingredient & Ratio by weight (\%) \\
\hline $\mathrm{SiO}_{2}$ & 46.17 \\
$\mathrm{Al}_{2} \mathrm{O}_{3}$ & 17.33 \\
$\mathrm{Fe}_{2} \mathrm{O}_{3}$ & 4.86 \\
$\mathrm{Mn}_{2} \mathrm{O}_{3}$ & 0.29 \\
$\mathrm{MgO}$ & 2.14 \\
$\mathrm{SO}$ & 0.18 \\
$\mathrm{CaO}$ & 13.5 \\
$\mathrm{Cl}$ & 0.10 \\
L.O.I. & 15.43 \\
\hline
\end{tabular}

Table 2 Different batching proportions of raw material for SCS-Brick*

\begin{tabular}{cccc}
\hline Brick Series & \multicolumn{3}{c}{ Percentage by weight, \% } \\
\hline & Sludge & Limestone & Cement \\
\cline { 2 - 4 } Control Brick & 0 & 60 & 40 \\
Series-A & 5 & 55 & 40 \\
Series-B & 7 & 53 & 40 \\
Series-C & 10 & 50 & 40 \\
Series-D & 15 & 45 & 40 \\
Series-E & 20 & 40 & 40 \\
Series-F & 25 & 35 & 40 \\
Series-G & 30 & 30 & 40 \\
\hline
\end{tabular}

* SCS-Brick: Lime, Cement and Sludge Brick

Table 3 Different batching proportions of raw materials for CS-Brick*

\begin{tabular}{ccc}
\hline Brick Series & \multicolumn{2}{c}{ Percentage by weight, \% } \\
\hline Series-H & Sludge & Cement \\
\cline { 2 - 3 } Series-I & 20 & 80 \\
Series-J & 25 & 75 \\
Series-K & 40 & 60 \\
Series-L & 50 & 50 \\
\hline *CS-Brick: Cement, Sludge Brick & 40 & 60 \\
\hline
\end{tabular}

* CS-Brick: Cement, Sludge Brick 


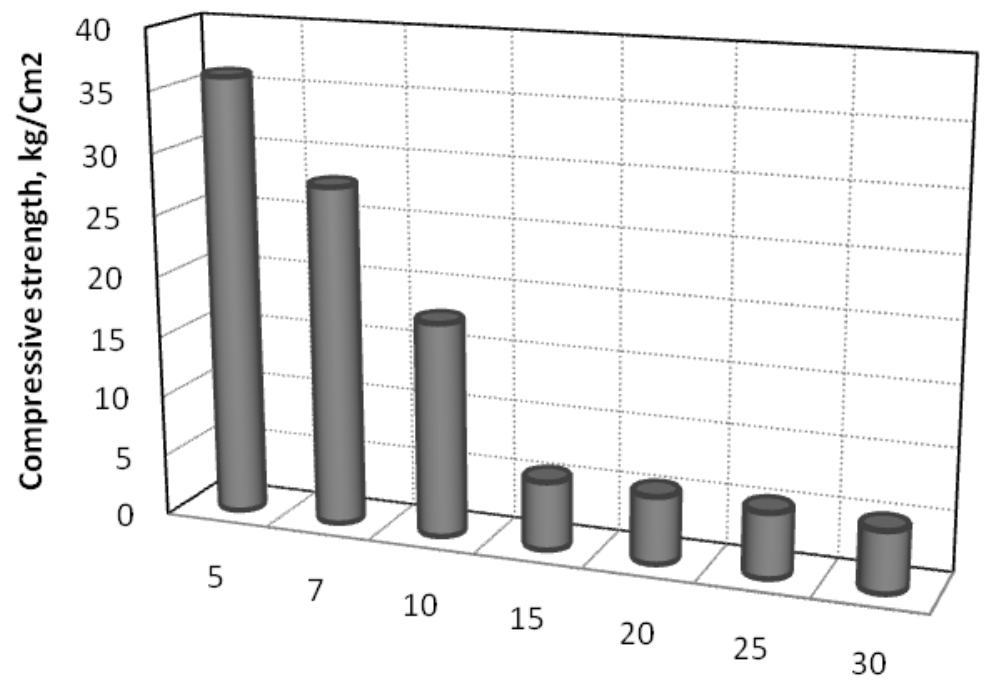

Sludge, \% by weight in the SCS-Bbrick

Fig. 1 Effect of sludge \% on the compressive strength on SCS-Brick

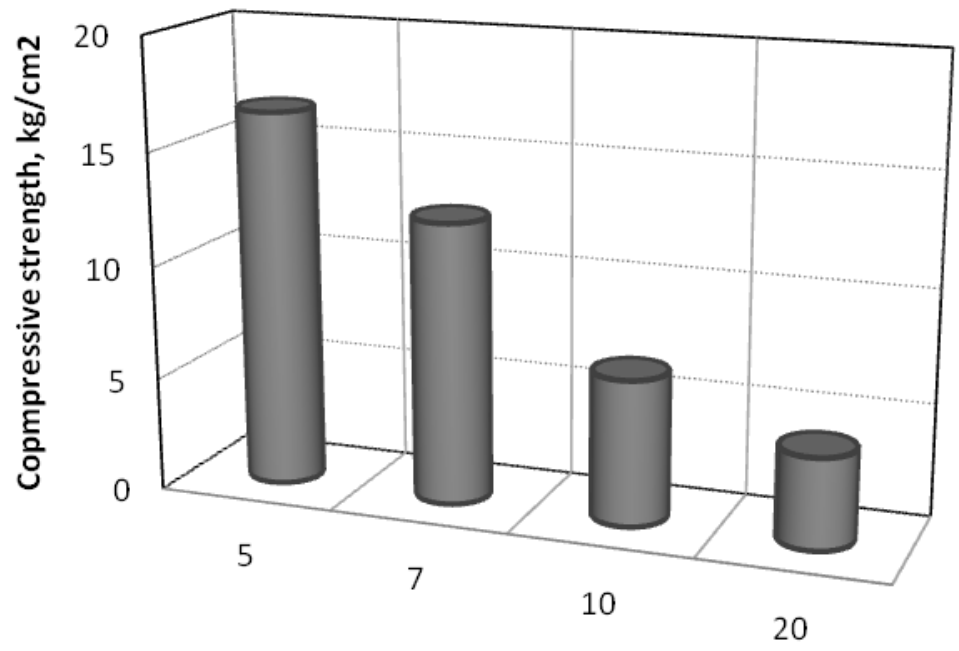

Sludge, $\%$ by weight in the SCS-Brick

Fig. 2 Effect of firing of the bricks on the compressive strength on SCS-Brick 


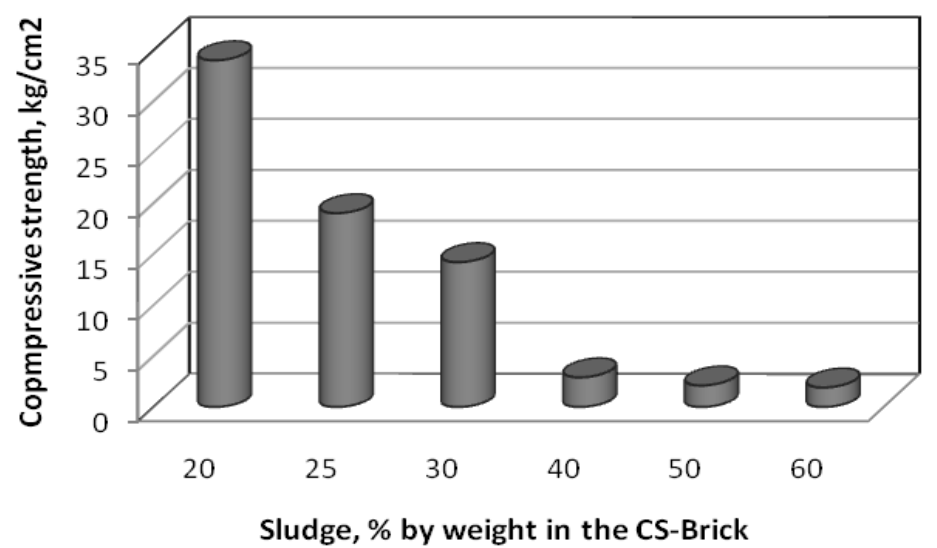

Fig. 3 Effect of sludge \% on the compressive strength on CS-Brick

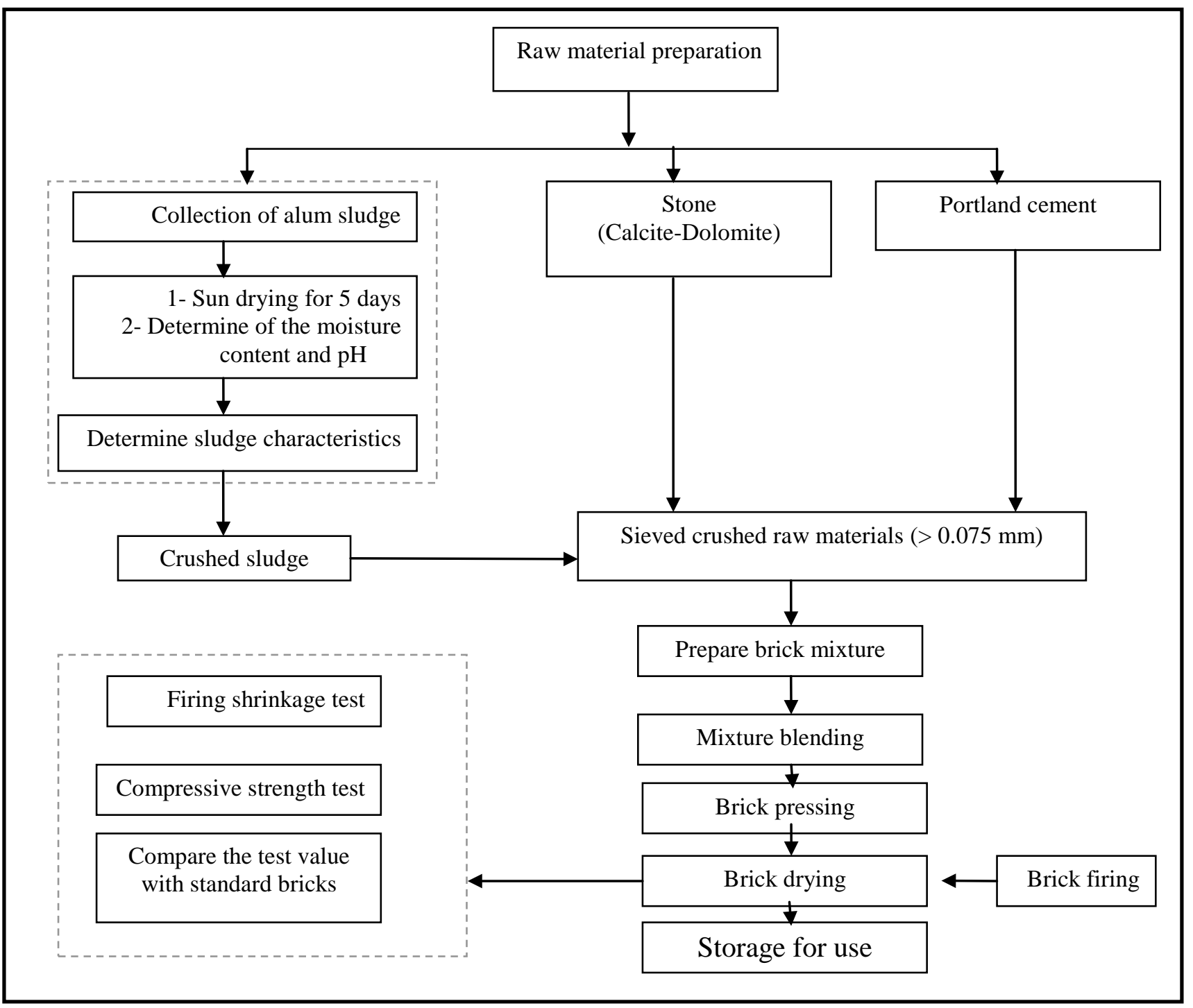

Fig. 4 Schematic diagram of the SCS-Brick manufacturing steps 